\section{D chromatin interactions organize Yan chromatin occupancy and repression at the even-skipped locus}

Jemma L. Webber, ${ }^{1}$ Jie Zhang, ${ }^{1,2}$ Aaron Mitchell-Dick, ${ }^{1}$ and Ilaria Rebay ${ }^{1,2,3}$

${ }^{1}$ Ben May Department for Cancer Research, University of Chicago, Chicago, Illinois 60637, USA; ${ }^{2}$ Committee on Cancer Biology, University of Chicago, Chicago, Illinois 60637, USA

Long-range integration of transcriptional inputs is critical for gene expression, yet the mechanisms remain poorly understood. We investigated the molecular determinants that confer fidelity to expression of the heart identity gene even-skipped (eve). Targeted deletion of regions bound by the repressor Yan defined two novel enhancers that contribute repressive inputs to stabilize tissue-specific output from a third enhancer. Deletion of any individual enhancer reduced Yan occupancy at the other elements, impacting eve expression, cell fate specification, and cardiac function. These long-range interactions may be stabilized by three-dimensional chromatin contacts that we detected between the elements. Our work provides a new paradigm for chromatin-level integration of general repressive inputs with specific patterning information to achieve robust gene expression.

Supplemental material is available for this article.

Received July 2, 2013; revised version accepted October 1, 2013.

Historically, eukaryotic enhancers have been characterized as DNA elements that are both necessary and sufficient to recapitulate endogenous gene expression. Many genes, particularly those with complex and dynamic expression patterns, are controlled by multiple enhancers (Bulger and Groudine 2011), with the final pattern reflecting additive outputs from individual autonomously functioning elements. The advent of genome-wide chromatin occupancy studies has revealed a far greater complexity to transcription factor-binding patterns than anticipated from this model, and the field remains in the early stages of deciphering the underlying functional relevance. For example, the contribution of nonadditive interactions between cis-regulatory elements to gene expression is just beginning to be appreciated, and the mechanistic importance of chromatin environment in organizing these interactions remains largely speculative (Frankel et al. 2010; Perry et al. 2010, 2011; Dunipace et al. 2011; He et al. 2011).

[Keywords: Drosophila; ETS transcription factor; chromatin conformation; gene regulation; heart development; robustness]

${ }^{3}$ Corresponding author

E-mail irebay@uchicago.edu

Article is online at http://www.genesdev.org/cgi/doi/10.1101/gad.225789.113.
The transcriptional effector switch that controls cell fate specification downstream from Ras/MAPK signaling provides a tractable vantage point for exploring these ideas (O'Neill et al. 1994; Gabay et al. 1996; Graham et al. 2010). The opposing action of two conserved ETS family transcription factors, the repressor Yan and the activator Pointed (Pnt), provides a bistable system that transitions from a high to a low Yan state to activate programs of gene expression that drive differentiation. For example, Yan and Pnt provide essential input to a combinatorial code that regulates expression of even-skipped (eve) during specification of the segmentally arrayed muscle and cardiac progenitors that arise in the dorsal mesoderm during embryonic stage 11 . While specification of these cells is reduced in pnt mutants and increased in yan mutants (Halfon et al. 2000; Knirr and Frasch 2001; Han et al. 2002), how the antagonistic transcriptional activities of Yan and Pnt are organized at the chromatin level is not understood.

Here we tested the hypothesis that long-range integration of Yan-mediated repression across a locus can stabilize the high Yan state to prevent inappropriate cell fate specification. Using regulation of mesodermal eve as the model, we found that targeted deletion of individual Yanbound elements disrupts Yan occupancy across the locus and identified a three-dimensional (3D) chromatin conformation that may stabilize these long-range interactions. Loss of coordinated Yan-mediated repression compromises the Yan-Pnt switch, as evidenced by increased variability of eve expression and impaired cell fate specification, cardiac function, and viability-all phenotypes that can be enhanced or suppressed by reducing the genetic dose of yan or pnt, respectively. We speculate that chromatinlevel integration of repressive inputs with specific patterning information may provide a broadly used mechanism to achieve robust gene expression.

\section{Results and Discussion}

In addition to the muscle/heart enhancer targeted by the Yan-Pnt switch (MHE) (Halfon et al. 2000), our genomewide occupancy study of Yan mapped three other regions to the eve locus (Webber et al. 2013). We refer to the four Yan-bound domains as D1, D2, D3/MHE, and D4. To explore the contribution of individual Yan-bound regions to mesodermal eve expression we recombineered specific deletions into a functional genomic bacterial artificial chromosome (BAC) construct encompassing the entire 16.4-kb eve locus carrying an in-frame YFP tag (Fig. 1A; Ludwig et al. 2011). As enhancer-blocking activity has previously been identified between the MHE and Ter94 gene (Fujioka et al. 2009), we reasoned that the D4 Yanbound element was more likely to contribute to Ter94 than to eve regulation and excluded it from our analysis. Transgenes were generated, and altered function was assessed by examining expression in the Eve-positive cardiogenic precursors. The simple prediction for deletion of a functional Yan-bound region is that loss of repression

(C) 2013 Webber et al. This article is distributed exclusively by Cold Spring Harbor Laboratory Press for the first six months after the full-issue publication date (see http://genesdev.cshlp.org/site/misc/terms.xhtml). After six months, it is available under a Creative Commons License (AttributionNonCommercial 3.0 Unported), as described at http://creativecommons.org/ licenses/by-nc/3.0/. 


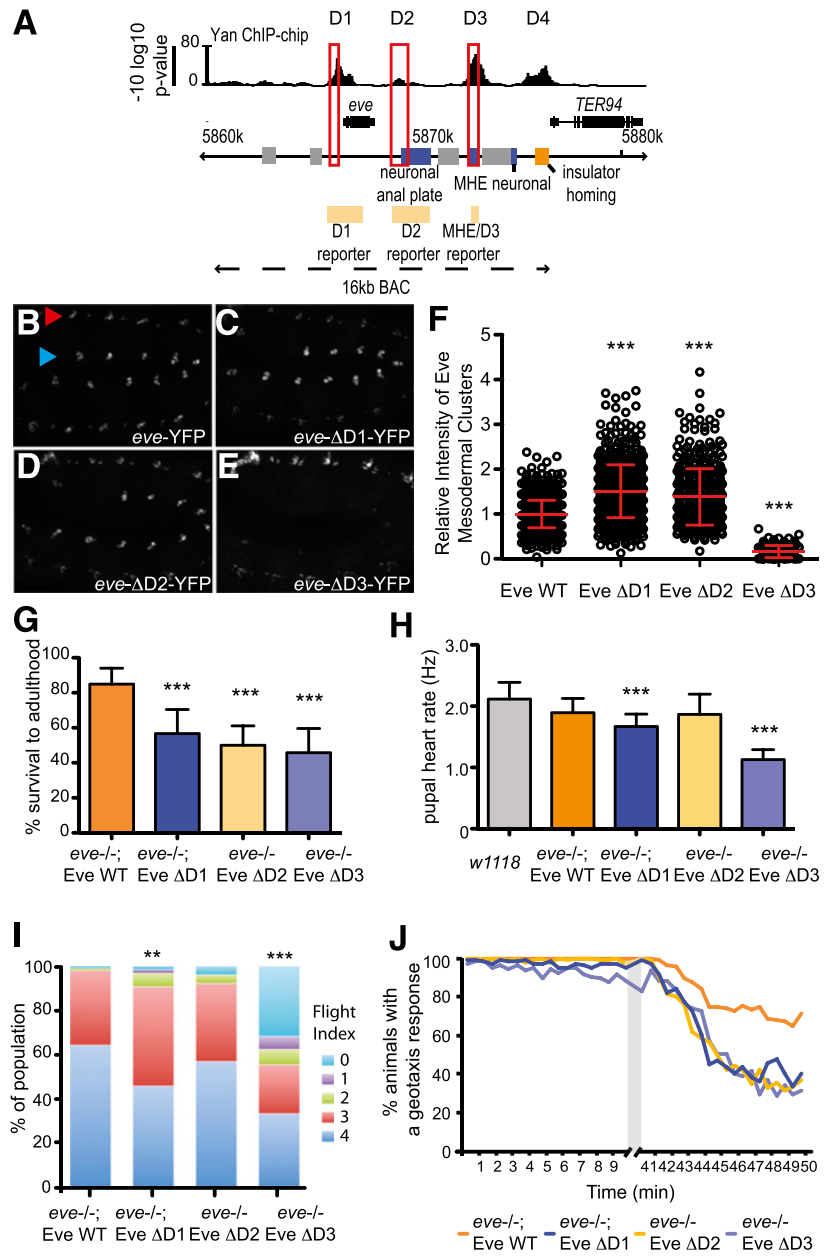

Figure 1. Yan-bound regions at the eve locus contribute to mesodermal expression, viability, and cardiac function. (A) Yan ChIP-chip patterns at eve. Yan binds to the proximal promoter (D1), a region that partially overlaps a cis-regulatory module responsible for neuronal and anal plate expression (D2), the previously characterized MHE (Halfon et al. 2000) (D3), and a region upstream of the TER94 locus (D4) that overlaps a previously characterized insulator and homing element (Fujioka et al. 2009). Red boxes depict engineered deletions. Gray boxes depict stripe enhancers. Light-orange boxes depict regions used for reporter constructs. $(B-E)$ Immunostaining of $e v e^{\mathrm{WT}}(B), e v e^{\Delta \mathrm{D} 1}(C), e v e^{\Delta \mathrm{D} 2}(D)$, and $e v e^{\Delta \mathrm{D} 3}(E)$ with antiGFP. Eve-YFP expression recapitulates wild-type eve expression in 11 clusters of cells in the mesoderm (blue arrowhead) and the CNS (red arrowhead). While $e v e^{\Delta \mathrm{D} 1}$ and $e v e^{\Delta \mathrm{D} 2}$ qualitatively reproduced $e v e^{\mathrm{WT}}$ expression, reduced expression was observed with $e v e^{\Delta \mathrm{D} 3}$. $(F) e v e^{\Delta \mathrm{DI}}, e v e^{\Delta \mathrm{D} 2}$ and $e v e^{\Delta \mathrm{D} 3}$ embryos were stained and fixed in parallel with $e v e^{\mathrm{W}^{\mathrm{T}}}$ embryos. Quantification of pixel intensity for each cluster relative to $e v e^{\mathrm{WT}}$ is depicted on the $Y$-axis. Mean intensity is indicated with a red line, and error bars indicate standard deviation. ( $n>30$ embryos; eve $e^{\mathrm{WT}}$ :eve $e^{\Delta \mathrm{D} 1}, P<0.0001$; eve $e^{\mathrm{WT}}$ :eve $e^{\Delta \mathrm{D} 2}$, $P<0.0001$; Mann-Whitney U; $n=12$ embryos; eve $e^{\mathrm{WT}}$ :eve $e^{\Delta \mathrm{D} 3^{\prime}}$, $P<0.0001) .(G)$ eve-null embryos [Df(2R)eve/eve $\left.{ }^{\mathrm{R} 13}\right]$ carrying the deletion transgenes were genotyped and cultured at $25^{\circ} \mathrm{C}$, and the number of adults that survived was counted $\left(n>350\right.$; eve $e^{\mathrm{WT}^{\mathrm{T}}}:$ eve $e^{\Delta \mathrm{D} 1}$, $P<0.0001 ;$ eve $^{\mathrm{WT}}:$ eve $e^{\Delta \mathrm{D} 2}, P<0.0001 ;$ eve $e^{\mathrm{WT}}$ :eve $\left.e^{\Delta \mathrm{D} 3}, P<0.0001\right)^{\prime}$. (H) Average heart rates of white prepupae. (eve $e^{\mathrm{WT}}:$ eve $e^{\Delta \mathrm{Dl}}, P<0.0001$; $e^{\text {eve }}{ }^{\mathrm{WT}}$ :eve $\mathrm{DD}^{\mathrm{D} 3}, P<0.0001$; Mann-Whitney U). (I) In the flight assay, a flight index of 4 is the highest possible score ${ }_{j} 0$ indicates no flying ability $\left(\right.$ eve $e^{\mathrm{WT}}: e v e^{\Delta \mathrm{D} 1}, P<0.01 ;$ eve ${ }^{\mathrm{WT}}:$ eve $e^{\Delta \mathrm{D} 3}, P<0.0001$; Mann-Whitney U). (J) $e v e^{\Delta \mathrm{D} 1}$ and $e v e^{\Delta \mathrm{D} 2}$ animals had a reduced negative geotaxis response compared with $e v e^{\mathrm{WT}}(n>100)$. should increase expression of the target gene; however, if the deletion also removes binding sites for critical activators, then reduced expression is expected. Either scenario predicts reduced ability to complement an eve-null. Alternatively, if elements are functional yet fully redundant under optimal conditions, no change in expression or viability is predicted.

The control eve-YFP transgene fully complemented an eve-null background, with $86 \%$ rescue to adulthood, and was expressed in a pattern identical to that of endogenous eve. Thus, in stage 11 embryos, Eve-YFP was prominent in the muscle and cardiogenic precursors as well as in clusters of neurons in the CNS (Fig. 1B). Deletion of the D1, D2, or D3 Yan-bound regions altered expression and reduced genetic rescue efficiency (Fig. 1C-G), indicating important contributions to regulation of eve. As predicted based on loss of key activating inputs (Halfon et al. 2000), deletion of the D3/MHE region significantly reduced mesodermal expression, with Eve ${ }^{\Delta \mathrm{D} 3}$-YFP expression detectable, on average, in only one cell per cluster (Figs. 1E, 2A). For the Eve ${ }^{\Delta \mathrm{D} 1}$-YFP and Eve ${ }^{\Delta \mathrm{D} 2}$-YFP transgenes, although expression in the mesoderm appeared qualitatively normal (Fig. 1B-D), quantification of the YFP signal revealed significant increases in both the mean intensity and embryo-to-embryo variation relative to the wild-type Eve-YFP control (Fig. 1F). The reduced ability of the deletion transgenes to rescue an eve-null (Fig. 1G) suggests that these Yan-bound elements are not redundant. The deleted regions do not include known stripe enhancers (Fig. 1A, gray boxes), and cuticle preparations of dead embryos from the rescue experiments did not show segmentation defects (data not shown). Thus, the reduced viability is unlikely attributed to axial patterning defects.

Precise regulation of eve expression in the cardiogenic mesoderm is essential for acquisition of heart cell identity and ultimately for cardiac function (Fujioka et al. 2005; Johnson et al. 2007). Consistent with this, the elevated expression of Eve ${ }^{\Delta D 1}$-YFP reflected in part an increase in the number of Eve-positive mesodermal cells specified (Fig. 2A), raising the possibility that compromised heart development might contribute to reduced fitness. To test this, we first measured pupal heart rates (Fig. 1H). In agreement with Fujioka et al. (2005), the heart rate of $e v e^{-9-} ; e v e^{\Delta \mathrm{D} 3}$-YFP animals was significantly reduced relative to the $e v e^{-/-}$; eve-YFP control. eve $e^{-/-}$; $e v e^{\Delta \mathrm{D} 1}$-YFP larvae also had a reduced heart rate, suggesting that the ectopic cell fate specification detected compromises the ensuing developmental program. Deletion of the D2 region did not significantly change the number of Eve-positive mesodermal cells specified, and the heart rate measured in $e v e^{-/-}$; eve $e^{\Delta \mathrm{D} 2}$ pupae was comparable with that of the control.

Adult heart function is commonly assessed with assays that measure the general vigor and activity of the fly (Fujioka et al. 2005; Piazza et al. 2009; Shahrestani et al. 2009). In both a flight assay and an assay measuring the negative geotaxis response before and after heat stress, $e v e^{-l-} ; e v e^{\Delta \mathrm{D} 3}-\mathrm{YFP}$ and $e v e^{-l-} ; e v e^{\Delta \mathrm{D} 1}$-YFP flies again performed poorly relative to eve $e^{-l-}$; eve-YFP control animals (Fig. 1I,J). eve $e^{-1-}$; eve $e^{\Delta \mathrm{D} 2}$-YFP animals exhibited a response intermediate to that of the $e v e^{-/-} ; e v e^{\Delta \mathrm{D} 1}$-YFP and control $e v e^{-/-}$; eve-YFP animals in the geotaxis assay prior to heat stress. However, after stress, the activity of $e v e^{-/-} ; e v e^{\Delta \mathrm{D} 2}$-YFP flies was significantly below that of 


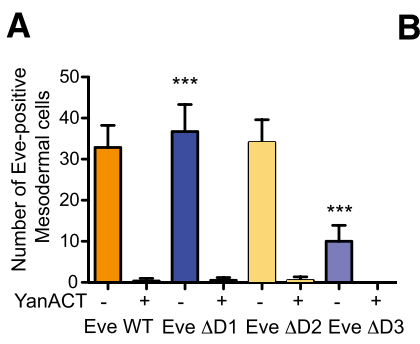

B
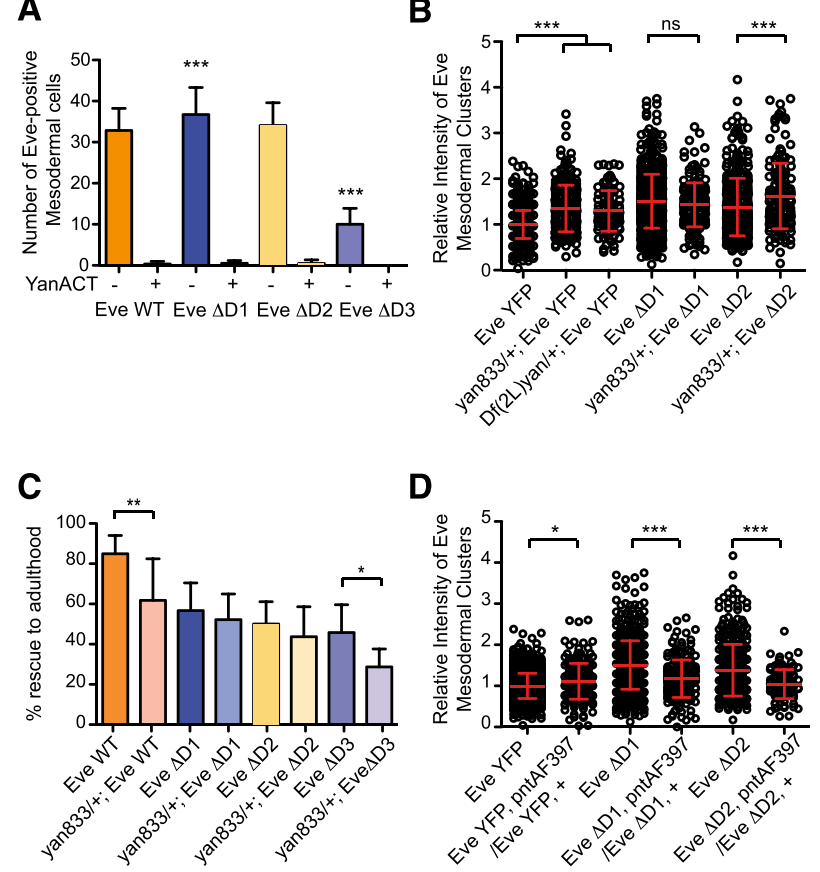

D
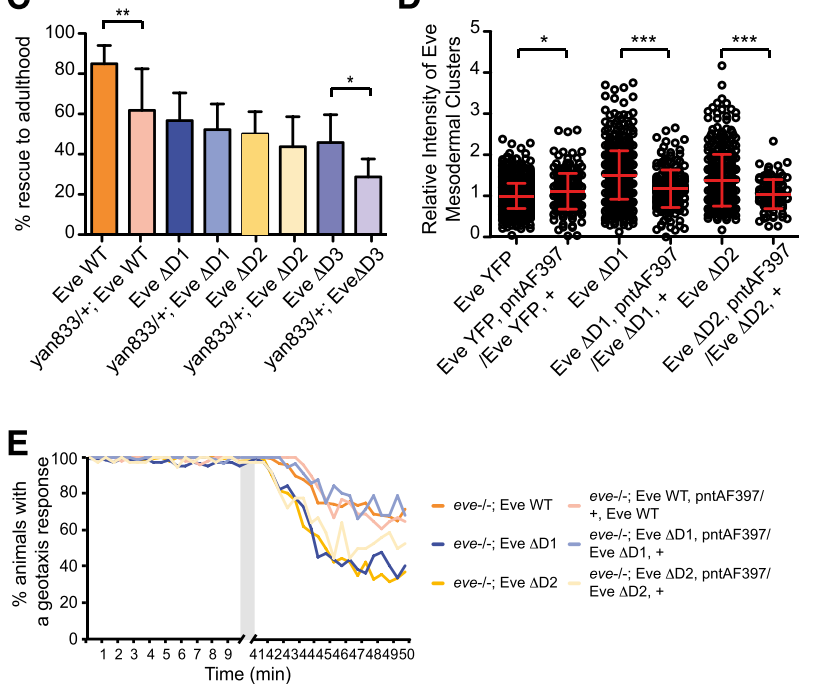

Figure 2. Robust regulation of mesodermal Eve expression depends on yan and pnt. (A) Eve-positive mesodermal cells were counted in $e v e^{\mathrm{WT}}, e v e^{\Delta \mathrm{D} 1}, e v e^{\Delta \mathrm{D} 2}$, and eve $e^{\Delta \mathrm{D} 3}$ embryos in the presence or absence of twist-Gal4>UAS Yan ${ }^{\text {ACT }}$. A statistically significant increase was observed in $e v e^{\Delta \mathrm{D} 1}$, and a reduced number was observed in $e v e^{\Delta \mathrm{D} 3}(n>70$ embryos; $P<0.0001$ and $P<0.0001$, respectively; Mann-Whitney U). (B) Quantification of Eve-YFP shows an increase in intensity and variation of expression in embryos heterozygous for yan $(n>10$ embryos; $P<0.0001$; ANOVA). Heterozygosity for yan further increased YFP intensity in $e v e^{\Delta \mathrm{D} 2}$ but not eve $e^{\Delta \mathrm{D} 1}(n>10$ embryos; $P<0.0001$; ANOVA). (C) Hand-genotyped eve-null embryos [Df(2R)eve/eve $\left.e^{\mathrm{R} 13}\right]$ or eve-null, yan heterozygous embryos $\left[\mathrm{Df}(2 \mathrm{R})\right.$ eve, yan ${ }^{833} /$ eve $\left.^{\mathrm{R} 13}\right]$ carrying the different deletion transgenes were cultured at $25^{\circ} \mathrm{C}$, and the number of eclosed adults was counted (n > 250; eve $e^{\mathrm{WT}}: \mathrm{yan}^{833} /+$; eve $\mathrm{WT}^{\mathrm{WT}} P=0.0007$; eve $e^{\Delta \mathrm{D} 3}: \mathrm{yan}^{833} /+$; eve $\left.e^{\Delta \mathrm{D} 3}, P=0.0013\right)$. (D) Quantification revealed an increase in Eve-YFP intensity in $e v e^{\Delta \mathrm{D} 1}$ and $e v e^{\Delta \mathrm{D} 2}$ embryos relative to eve $e^{\mathrm{WT}}$ $(P<0.0001)$. No significant difference was observed between $e v e^{\Delta \mathrm{D} 1}$ or $e v e^{\Delta \mathrm{D} 2}$ and $e v e^{\mathrm{WT}}$ Eve-YFP expression in pnt heterozygotes. $(E)$ Flies of the indicated genotype were subjected to a geotaxis response assay. Heterozygosity for pnt restored the response of $e v e^{\Delta \mathrm{D} 1}$ to that of an $e v e^{\mathrm{WT}}$ control $(n>50)$ and improved that of $e v e^{\Delta \mathrm{D} 2}(n>35)$.

the control. Together, these results confirm the physiological importance of the Yan-bound D1 region and support the hypothesis that it mediates repressive inputs important for stabilizing mesodermal eve expression within levels required to support normal cell fate acquisition during heart development. As the D2 deletion partially overlaps a neuronal enhancer, further analysis will be required to determine whether the reduced fitness and activity result from either compromised neural function, subtle cardiac defects, or a combination of the two.

To obtain more direct evidence that compromised Yanmediated repression contributes to increased expression and reduced fitness of the deletion mutants, we first tested the effectiveness of twist-Gal4-driven overexpression of a constitutively active form of Yan, Yan ${ }^{\text {ACT }}$ (Rebay and Rubin 1995), in repressing expression of the deletion transgenes. If Yan-mediated repressive inputs act exclusively on the MHE, then Yan ${ }^{\mathrm{ACT}}$ should repress mesodermal expression of Eve $e^{\Delta \mathrm{D} 1}$-YFP and Eve $\mathrm{D}^{\Delta \mathrm{D} 2}$-YFP but not $\mathrm{Eve}^{\Delta \mathrm{D} 3}$ YFP. Alternatively, if Yan-mediated regulation across multiple genomic elements contributes to stable eve expression, then all deletion transgenes should be sensitive to Yan ${ }^{\mathrm{ACT}}$. Our results support the latter scenario, as Yan $^{\text {ACT }}$ fully repressed all three eve-YFP deletion transgenes (Fig. 2A).

We next asked whether heterozygosity for yan or pnt might, respectively, enhance or suppress the loss of robustness measured for the eve deletion constructs. Using either a null allele or a small deficiency, we found that heterozygosity for yan increased the mean intensity and variation of wild-type Eve-YFP expression and further increased the intensity of $\mathrm{Eve}^{\Delta \mathrm{D} 2}$-YFP expression (Fig. 2B). While yan heterozygosity did not significantly increase $\mathrm{Eve}^{\Delta \mathrm{DI}}$-YFP expression, the number of Eve-positive cells specified was increased (Supplemental Fig. S1). These changes also impact fitness, as yan heterozygosity further reduced the genetic rescue efficiency of the eve transgenes (Fig. 2C). Conversely, heterozygosity for pnt suppressed the increased intensity and variability of $\mathrm{Eve}^{\Delta \mathrm{D} 1}$-YFP and $\mathrm{Eve}^{\Delta \mathrm{D} 2}$-YFP expression (Fig. 2D; Supplemental Fig. S1). A reduced pnt dose also improved the negative geotaxis response following heat shock (Fig. 2E). Together, these results suggest that the D1 and D2 elements are required for robust regulation of eve expression in the muscle and cardiogenic precursors such that loss of Yan-mediated repression upon deletion of either element permits inappropriate Pnt-mediated activation of eve, presumably through the MHE, leading to increased and more variable expression. Such destabilization of the Yan-Pnt switch makes the system prone to aberrant cell fate specification and ultimately reduces fitness.

To explore further the properties of the D1 and D2 Yanbound regions, we asked whether they define autonomous cis-regulatory elements or whether their activity requires the endogenous genomic context. Reporter constructs carrying sequences spanning the chromatin immunoprecipitation (ChIP)-defined Yan-bound regions were generated (Fig. 1A), and expression was examined in stage 11 embryos. In contrast to the control MHE reporter that expressed specifically in the expected mesodermal clusters, the D1 and D2 reporters showed weak ubiquitous expression (Fig. 3A). A slightly stronger signal was detected in the mesoderm for both reporters but in domains broader than the three cell clusters seen with the MHE reporter. Removing yan increased the intensity but not the specificity of the expression patterns of the D1 and D2 reporters, suggesting that the individual elements can be recognized and repressed by Yan outside of the context of the intact eve locus. The autonomous ability of each element to recruit Yan was confirmed by ChIP-PCR, although quantitative PCR (qPCR) analysis revealed that 
A

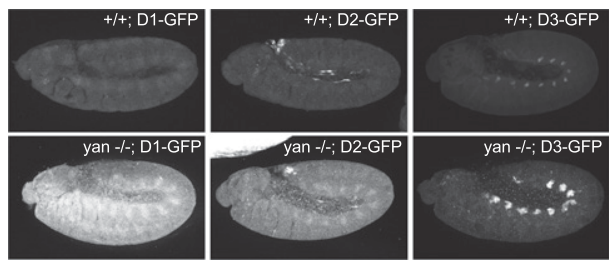

B

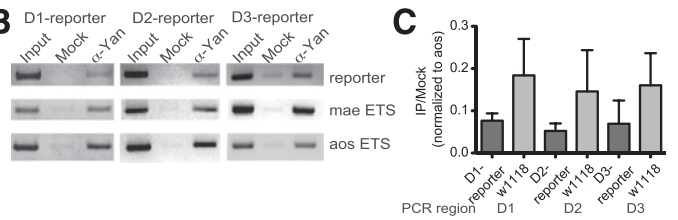

Figure 3. Regions $\mathrm{D} 1$ and $\mathrm{D} 2$ are sufficient to recruit Yan but not to drive specific mesodermal expression. (A) Analysis of GFP expression of the D1, D2, and D3 reporters (depicted in Fig. 1A) in a wildtype or $\mathrm{yan}^{-1-}\left(\mathrm{y}^{E R}{ }^{E 433}\right)$ background; staining and imaging of each pair was done in parallel. The D3/MHE reporter expressed strongly and specifically in the mesodermal clusters. The D1 and D2 reporter expression was weak and ubiquitous with only slight mesodermal enrichment. Expression intensity increased for all reporters in $\mathrm{yan}^{-1-}$ (B) ChIP-PCR shows Yan enrichment at the D1, D2, and D3 reporters. To the distinguish reporter from the endogenous locus, primer pairs included one within the reporter and one from the $86 \mathrm{Fb}$ integration site. Enrichment at argos (aos) and mae provided positive controls. (C) ChIP-qPCR showed less efficient Yan recruitment to the reporters relative to the endogenous eve locus. Data are plotted relative to Yan occupancy at aos. Error bars are mean \pm standard deviation $(n=4)$.

occupancy was reduced relative to that measured at the endogenous locus (Fig. 3B,C).

Because the D1 and D2 Yan-bound elements do not appear to provide independent additive inputs capable of directing mesodermal eve expression, we wondered whether their primary role might be to integrate Yanrepressive inputs across the intact locus. We hypothesized that long-range interactions between these regions might stabilize Yan binding, thereby providing a buffering mechanism that sets the precise MHE-driven eve expression pattern needed for accurate cell fate specification. If correct, then deletion of any individual Yan-bound region not only should abolish occupancy at the site of deletion, but might also perturb binding at the remaining elements. To test this, we assessed Yan occupancy by ChIP-qPCR in embryos homozygous for the eve deficiency and carrying the deletion transgenes. Supporting the model of coordinated stabilization of Yan occupancy, deletion of any individual Yan-bound domain reduced Yan occupancy by about twofold at the remaining two eve elements but did not alter enrichment at a distant locus (Fig. 4A,B; Supplemental Fig. S2). Thus, precise regulation of mesodermal eve expression relies on long-range coordination between cis-regulatory elements rather than additive inputs from autonomous enhancers.

One possible mechanism is that the $3 \mathrm{D}$ chromatin environment facilitates interactions between the D1, D2, and D3 elements. Using proximity ligation and PCR analysis (referred to as chromatin conformation capture [3C]), we detected a long-range interaction between a D1D2 fragment and the D3/MHE fragment (Fig. 4A,C,D). Sequencing confirmed the expected identity of the amplified ligated fragment. Control primers located just outside of the eve locus did not yield a 3C product with the D1-D2 fragment (Fig. 4D; Supplemental Fig. S3A,B).
Furthermore, the $3 \mathrm{C}$ interaction was not detected in adult heads, suggesting context-specific chromatin contacts (Supplemental Fig. S3C-E). Finer-scale mapping in both wild-type and yan mutant embryos should provide further insight into how the 3D chromatin environment facilitates cooperative recruitment of Yan across the locus and how this in turn both stabilizes the Yan-Pnt switch in optimal conditions and buffers against genetic or environmental variation that might limit Yan.

In conclusion, our results suggest a novel regulatory mechanism in which, rather than contributing patterning information, the D1 and D2 enhancers act to dampen the expression control mediated by the D3/MHE. More broadly, this raises the possibility that even when transcription factor-bound regions identified through ChIP sequencing (ChIP-seq) fail to give clear expression patterns as autonomous reporters, they may still contribute to gene regulation in vivo. In the case of Yan, we speculate that its intrinsic polymerization ability (Qiao et al. 2004; Song et al. 2005; Zhang et al. 2010) allows it to exploit the $3 \mathrm{D}$ chromatin environment to organize long-range repressive complexes that coordinate information across multiple enhancers.
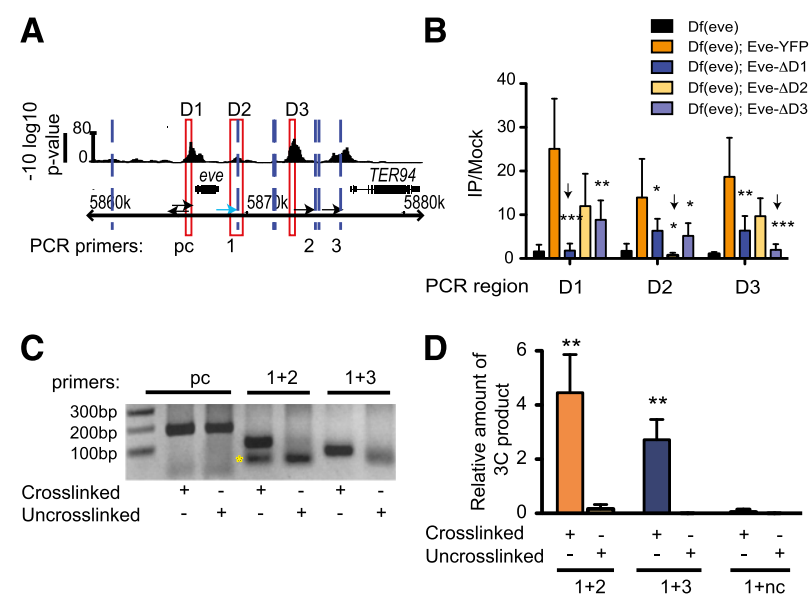

Figure 4. Yan binds cooperatively to individual regions across the eve locus. (A) Depiction of the Yan ChIP pattern at the eve locus. Red boxes indicate regions deleted, blue dashed lines depict EcoR1 sites, and arrows indicate PCR primers used for 3C analysis. $(B)$ ChIP-qPCR shows enrichment was lost at the site of deletion (arrow). A consistent decrease in enrichment at the other Yan-bound regions was observed in all deletions relative to $e v e^{\mathrm{WT}}$. Error bars are mean \pm standard deviation. $(C)$ Forward and reverse primers located in the D1 region provided a PCR-positive control (pc), amplifying a fragment in both cross-linked and uncross-linked DNA. A PCR product from a primer located at the end of the fragment containing the D1 and part of the D2 region (primer 1; light blue arrow) and a primer located at the $3^{\prime}$ end of the MHE (primer 2) fragment was observed only in the cross-linked sample. Asterisk indicates primerdimer. A PCR product from primer 1 and a primer located at the $3^{\prime}$ end of a fragment containing the neuronal enhancer but not the insulator/homing element (primer 3) was also observed in the crosslinked sample. Sequencing confirmed the predicted ligated products. $(D)$ ChIP-qPCR of cross-linked and uncross-linked samples. The relative amount of $3 \mathrm{C}$ product was determined for primer pairs $1+2$, $1+3$, and $1+$ nc (nc primer located to the right of the insulator element) (see Supplemental Fig. S3A), and values were plotted relative to a positive control. Error bars are mean \pm standard deviation $(n=3$; cross-linked $1+2$ :uncross-linked $1+2, P=$ 0.0015 ; cross-linked $1+3$ :uncross-linked $1+3, P=0.0007$; crosslinked $1+$ nc:uncross-linked $1+$ nc, $P=0.2723$ ). 
Many parallels can be drawn between Yan/Pnt regulation of the transition from uncommitted progenitor to specified cell fate within a developing tissue and the control of the pluripotent state in mammalian cells. Given the potential for natural, genetic, or environmental variation to perturb the timing, accuracy, or stability of such transitions, mechanisms to impart robustness to gene expression are almost certainly required and very likely conserved across species. Thus, the regulatory paradigm established in this study may be broadly relevant.

\section{Materials and methods}

\section{Deletion transgenes and GFP reporters}

A BAC containing the eve locus (Ludwig et al. 2011) was modified to generate the D1, D2, and D3 deletions using the Counter-Selection BAC Modification kit (Gene Bridges) following the manufacturer's protocol. The genomic coordinates for the Eve deletions D1, D2, and D3 were 2R: 5866200-5866500; 2R: 5869000-5869800; and 2R: 5872789-5873131, respectively. Subcloning via the BAC Subcloning kit (Gene Bridges) into the transformation vector and site-specific integration in the attP2 site on the third chromosome (Groth et al. 2004) were performed as described in Ludwig et al. (2011). Reporter constructs were generated by inserting the D1 (2R: 5865760-5867730), D2 (2R: 5868845-5870866), and MHE (2R: 5872818-5873045) sequences into the pJR20 plasmid upstream of a minimal promoter and the GFP gene coding sequence. Site-specific integration into the $86 \mathrm{Fb}$ site on the third chromosome was as described in Bischof et al. (2007).

\section{Fly strains and genetics}

$e v e^{-/-} ;$eve-YFP, $e v e^{-/-} ; e v e^{\Delta \mathrm{D} 1}, e v e^{-/-} ; e v e^{\Delta \mathrm{D} 2}$, or $e v e^{-/-} ;$eve $e^{\Delta \mathrm{D} 3}$ embryos were selected from the cross of $\mathrm{Df}(2 \mathrm{R})$ eve (Bloomington Stock Center, no. $1545 / / C y o$, twist-Gal4, UAS-GFP (CTG); eve $\left(^{\mathrm{WT}}, \Delta \mathrm{D} 1, \Delta \mathrm{D} 2\right.$, or $\left.\Delta \mathrm{D} 3\right)$, and $\mathrm{eve}^{\mathrm{R} 13} / \mathrm{CTG}$; eve( ${ }^{\mathrm{WT}}, \Delta \mathrm{D} 1, \Delta \mathrm{D} 2$, or $\left.{ }^{\Delta \mathrm{D} 3}\right)$. CTG-negative embryos heterozygous for yan and homozygous for the eve deletion of interest were selected from the cross between either yan ${ }^{833} / \mathrm{CTG}$; eve $\left.\right|^{\mathrm{WT}}, \Delta \mathrm{D} 1$, or $\left.{ }^{\Delta \mathrm{D} 2}\right)$ or $\mathrm{Df}(2 \mathrm{~L}) \mathrm{yan} /$ CTG; eve $\left({ }^{\mathrm{WT}}\right.$ or $\left.{ }^{\Delta \mathrm{D} 1}\right)$ and $+/+$; eve $\left(^{\mathrm{WT}},{ }^{\Delta \mathrm{D} 1}\right.$, or $\left.{ }^{\Delta \mathrm{D} 2}\right)$.

To analyze eve-YFP expression in embryos heterozygous for pnt, Ubx-lacZnegative embryos were selected from a cross of $p n t^{\mathrm{AF} 397}$, eve $\left.\right|^{\mathrm{WT}},{ }^{\Delta \mathrm{D} 1}$, or ${ }^{\Delta \mathrm{D} 2}$ )/ $\mathrm{TM} 3$, Ubx-lacZ and $+/+$; eve ${ }^{\mathrm{WT}}, \Delta \mathrm{D} 1$, or $\left.\Delta \mathrm{D} 2\right)$. Alternatively, TTGnegative embryos were examined from a cross of $p n t^{\Delta 88} / \mathrm{TM} 3$, twistGal4, UAS-GFP (TTG), and $e v e^{\mathrm{WT}}$, eve $e^{\Delta \mathrm{D} 1}$, or $+/+$. To determine the effect of yan and pnt heterozygosity on the ability of eve $\left({ }^{\mathrm{WT}}, \Delta \mathrm{D} 1\right.$, or ${ }^{\Delta \mathrm{D} 2}$ ) to rescue an eve-null, CTG-negative embryos were hand-selected from a cross of Df(2R)eve, yan ${ }^{833} / \mathrm{CTG}$; eve ${ }^{\mathrm{WT}}, \Delta \mathrm{D} 1, \Delta \mathrm{D} 2$, or $\left.{ }^{\Delta \mathrm{D} 3}\right)$, and eve $\mathrm{e}^{\mathrm{R} 13}$ / $\mathrm{CTG} ;$ eve $\left.\right|^{\mathrm{WT}}, \Delta \mathrm{D} 1, \Delta \mathrm{D} 2$, or $\left.{ }^{\Delta \mathrm{D} 3}\right)$ or $\mathrm{Df}(2 \mathrm{R})$ eve $/ \mathrm{CTG} ; p^{\mathrm{AF} 397},\left.e v e\right|^{\mathrm{WT}},{ }^{\Delta \mathrm{D} 1}$ or ${ }^{\Delta \mathrm{D} 2}$ ), and eve ${ }^{\mathrm{R} 13} / \mathrm{CTG}$; eve ${ }^{\mathrm{WT}}, \Delta \mathrm{D} 1$, or ${ }^{\Delta \mathrm{D} 2}$ ). For ChIP-qPCR at the eve locus, $\sim 400$ CTG-negative embryos were selected from the progeny of $\mathrm{Df}(2 \mathrm{R})$ eve/CTG; Evel ${ }^{\mathrm{WT}}, \Delta \mathrm{D} 1, \Delta \mathrm{D} 2$, or $\left.{ }^{\Delta \mathrm{D} 3}\right)$.

\section{Quantification of Eve-YFP expression}

Stage 11 embryos were stained as described in Webber et al. (2013) with rabbit anti-GFP (1:1000; Invitrogen). Using a Zeiss 510 confocal microscope, serial $0.8-\mu \mathrm{m}$ z-sections were taken through the Eve-positive mesodermal cells, and maximum was projected using LSM software. Expression intensity was calculated as the mean pixel intensity for the cluster minus the mean background pixel intensity. Measurements were normalized to $e v e^{\mathrm{WT}}$. Column statistics are shown in Supplemental Table 1.

\section{Heart rate measurement}

The number of heartbeats of white prepupae in a 15 -sec period was determined as described in Cooper et al. 2009) and charted as hertz (cycles per second).

\section{Flight assay}

Flies were tapped into a 1000-mL graduated cylinder coated with mineral oil as described in Cauchi et al. (2008). The cylinder was divided into four quadrants, with the highest denoted as 4 and the lowest denoted as 1 . Flies that fell through without touching the sides were scored as 0 .

\section{Negative geotaxis response}

Assays were performed essentially as described in Tong et al. (2007) and Shahrestani et al. (2009). Ten 2- to 3-d-old males per genotype were collected into individual culture vials, and a horizontal line was drawn $1 \mathrm{~cm}$ above the food. Flies were knocked to the bottom, and after $15 \mathrm{sec}$, the number that climbed above the $1-\mathrm{cm}$ line scored. This was repeated every $30 \mathrm{sec}$ for $10 \mathrm{~min}$ to establish a baseline response. Animals were then subjected to a $30-\mathrm{min}$ heat shock at $37^{\circ} \mathrm{C}$ and returned to room temperature, and the geotaxis response was determined as they recovered. This assay was repeated until $n$-values of $>100$ were achieved for eve-YFP, $e v e^{\Delta \mathrm{D} 1}, e v e^{\Delta \mathrm{D} 2}$, and $e v e^{\Delta \mathrm{D} 3} ;>50$ were achieved for eve-YFP, pnt, and eve $e^{\Delta \mathrm{D} 1}$, pnt; and $>35$ were achieved for $e v e^{\Delta \mathrm{D} 2}$ and pnt.

\section{ChIP}

ChIPs from stage 11 embryos $\left(5 \mathrm{~h} 20-7 \mathrm{~h} 20\right.$ at $\left.25^{\circ} \mathrm{C}\right)$ were performed as described in Webber et al. ( 2013). Analysis of Yan binding to the D1, D2, and MHE GFP reporters was performed with a primer specific to the pJR20 plasmid and a primer specific to the D1, D2, or MHE sequence. ChIPqPCR was performed using the QuantiTech SYBR Green PCR kit (Qiagen). A standard curve for each primer pair was generated using serial dilutions of genomic DNA. The relative amounts of input, mock-treated, and immunoprecipitated DNA were determined based on the standard curves, and the ChIP signals were calculated as immunoprecipitation/ mock ratios. Each individual mock-treated and immunoprecipitation sample was derived from the same set of cross-linked embryos.

\section{$3 C$}

Cross-linking was performed as described in Webber et al. ( 2013) but for $20 \mathrm{~min}$. Embryos were homogenized in buffer A $15 \mathrm{mM} \mathrm{HEPES}$ at $\mathrm{pH} 7.6$, $10 \mathrm{mM} \mathrm{KCl}, 5 \mathrm{mM} \mathrm{MgCl} 2,0.1 \mathrm{mM}$ EDTA, $0.5 \mathrm{mM}$ EGTA, $350 \mathrm{mM}$ sucrose, $1 \mathrm{mM}$ DTT) and centrifuged for $15 \mathrm{~min}$ at 10,000 rpm. The pellet was resuspended in 1.5 $\times$ EcoRI buffer (New England Biolabs) with BSA and incubated for $30 \mathrm{~min}$ at $37^{\circ} \mathrm{C}$ with $3 \mu \mathrm{L}$ of $10 \%$ SDS. Following $20 \mathrm{~min}$ at $65^{\circ} \mathrm{C}, 20 \mu \mathrm{L}$ of $10 \% \mathrm{TX}-100$ was added, and samples were incubated for $1 \mathrm{~h}$ at $37^{\circ} \mathrm{C}$. Four microliters of EcoRI $(20,000 \mathrm{U} / \mathrm{mL}$; New England Biolabs) was added and incubated overnight at $37^{\circ} \mathrm{C}$ and digestion was stopped by adding $16 \mu \mathrm{L}$ of $10 \%$ SDS and incubating for $20 \mathrm{~min}$ at $65^{\circ} \mathrm{C}$. Digested chromatin was diluted in ligation buffer $(50 \mathrm{mM}$ Tris at $\mathrm{pH} 7.8$, $20 \mathrm{mM}$ DTT, $1 \mathrm{mM}$ ATP, $25 \mu \mathrm{g} / \mathrm{mL}$ BSA) with $1 \%$ TX100 to quench the SDS. Following $1 \mathrm{~h}$ of incubation at $37^{\circ} \mathrm{C}, 2 \mu \mathrm{L}$ of T4 DNA ligase $(400,000$ $\mathrm{U} / \mathrm{mL}$; New England Biolabs) was added, and samples were incubated overnight at $16^{\circ} \mathrm{C}$. Three microliters of Proteinase $\mathrm{K}$ (Invitrogen) was added prior to incubation overnight at $65^{\circ} \mathrm{C}$. DNA was purified by phenol/ chloroform extraction and ethanol precipitation, and ligation products were analyzed by PCR or qPCR.

\section{Statistical analyses}

Analyses were performed with Prism 5. A D'Agostino-Pearson normality test was used to determine whether the data fit a Gaussian distribution. A $t$-test or an ANOVA was performed on normally distributed data. Alternatively, a Mann-Whitney U or a Kruskal-Wallis test was used. A Dunn-corrected $P$-value is reported for statistical tests carried out on multiple data sets. The $\alpha$ level for all tests was 0.05 .

\section{Acknowledgments}

We thank Alec Victorsen and Ralf Kittler for recombineering the eve constructs, and Claude Desplan for the gift of pJR20. We thank members of the Rebay, Fehon, White, Reinitz, Kreitman, and Carthew laboratories for helpful discussions, and Rick Fehon, Trevor Davis, and Charlene Hoi for comments on the manuscript. I.R. is supported by National Institutes of Health (NIH) grants P50 GMO81892 and R01 GM080372. J.L.W. is supported by an award from the American Heart Association. J.Z is a recipient of a University of Chicago Women's Board Fellowship. 


\section{References}

Bischof J, Maeda RK, Hediger M, Karch F, Basler K. 2007. An optimized transgenesis system for Drosophila using germ-line-specific $\phi \mathrm{C} 31$ integrases. Proc Nat1 Acad Sci 104: 3312-3317.

Bulger M, Groudine M. 2011. Functional and mechanistic diversity of distal transcription enhancers. Cell 144: 327-339.

Cauchi RJ, Davies KE, Liu JL. 2008. A motor function for the DEAD-box RNA helicase, Gemin3, in Drosophila. PLoS Genet 4: e1000265.

Cooper AS, Rymond KE, Ward MA, Bocook EL, Cooper RL. 2009. Monitoring heart function in larval Drosophila melanogaster for physiological studies. J Vis Exp doi: 10.3791/1596.

Dunipace L, Ozdemir A, Stathopoulos A. 2011. Complex interactions between cis-regulatory modules in native conformation are critical for Drosophila snail expression. Development 138: 4075-4084.

Frankel N, Davis GK, Vargas D, Wang S, Payre F, Stern DL. 2010. Phenotypic robustness conferred by apparently redundant transcriptional enhancers. Nature 466: 490-493.

Fujioka M, Wessells RJ, Han Z, Liu J, Fitzgerald K, Yusibova GL, Zamora M, Ruiz-Lozano P, Bodmer R, Jaynes JB. 2005. Embryonic even skipped-dependent muscle and heart cell fates are required for normal adult activity, heart function, and lifespan. Circ Res 97: 1108-1114.

Fujioka M, Wu X, Jaynes JB. 2009. A chromatin insulator mediates transgene homing and very long-range enhancer-promoter communication. Development 136: 3077-3087.

Gabay L, Scholz H, Golembo M, Klaes A, Shilo BZ, Klambt C. 1996. EGF receptor signaling induces pointed $\mathrm{P} 1$ transcription and inactivates Yan protein in the Drosophila embryonic ventral ectoderm. Development 122: 3355-3362.

Graham TG, Tabei SM, Dinner AR, Rebay I. 2010. Modeling bistable cellfate choices in the Drosophila eye: Qualitative and quantitative perspectives. Development 137: 2265-2278.

Groth AC, Fish M, Nusse R, Calos MP. 2004. Construction of transgenic Drosophila by using the site-specific integrase from phage $\varphi \mathrm{C} 31$. Genetics 166: 1775-1782.

Halfon MS, Carmena A, Gisselbrecht S, Sackerson CM, Jimenez F, Baylies MK, Michelson AM. 2000. Ras pathway specificity is determined by the integration of multiple signal-activated and tissuerestricted transcription factors. Cell 103: 63-74.

Han Z, Fujioka M, Su M, Liu M, Jaynes JB, Bodmer R. 2002. Transcriptional integration of competence modulated by mutual repression generates cell-type specificity within the cardiogenic mesoderm. Dev Biol 252: 225-240.

He Q, Bardet AF, Patton B, Purvis J, Johnston J, Paulson A, Gogol M, Stark A, Zeitlinger J. 2011. High conservation of transcription factor binding and evidence for combinatorial regulation across six Drosophila species. Nat Genet 43: 414-420.

Johnson AN, Burnett LA, Sellin J, Paululat A, Newfeld SJ. 2007. Defective decapentaplegic signaling results in heart overgrowth and reduced cardiac output in Drosophila. Genetics 176: 1609-1624.

Knirr S, Frasch M. 2001. Molecular integration of inductive and mesoderm-intrinsic inputs governs even-skipped enhancer activity in a subset of pericardial and dorsal muscle progenitors. Dev Biol 238: $13-26$.

Ludwig MZ, Manu , Kittler R, White KP, Kreitman M. 2011. Consequences of eukaryotic enhancer architecture for gene expression dynamics, development, and fitness. PLoS Genet 7: e1002364.

O'Neill EM, Rebay I, Tjian R, Rubin GM. 1994. The activities of two Etsrelated transcription factors required for Drosophila eye development are modulated by the Ras/MAPK pathway. Cell 78: 137-147.

Perry MW, Boettiger AN, Bothma JP, Levine M. 2010. Shadow enhancers foster robustness of Drosophila gastrulation. Curr Biol 20: 1562-1567.

Perry MW, Boettiger AN, Levine M. 2011. Multiple enhancers ensure precision of gap gene-expression patterns in the Drosophila embryo. Proc Natl Acad Sci 108: 13570-13575.

Piazza N, Gosangi B, Devilla S, Arking R, Wessells R. 2009. Exercisetraining in young Drosophila melanogaster reduces age-related decline in mobility and cardiac performance. PLOS ONE 4: e5886.

Qiao F, Song H, Kim CA, Sawaya MR, Hunter JB, Gingery M, Rebay I, Courey AJ, Bowie JU. 2004. Derepression by depolymerization; structural insights into the regulation of Yan by Mae. Cell 118: 163-173.
Rebay I, Rubin GM. 1995. Yan functions as a general inhibitor of differentiation and is negatively regulated by activation of the Ras1/ MAPK pathway. Cell 81: 857-866.

Shahrestani P, Leung HT, Le PK, Pak WL, Tse S, Ocorr K, Huang T. 2009. Heterozygous mutation of Drosophila Opal causes the development of multiple organ abnormalities in an age-dependent and organspecific manner. PLOS ONE 4: e6867.

Song H, Nie M, Qiao F, Bowie JU, Courey AJ. 2005. Antagonistic regulation of Yan nuclear export by Mae and Crm1 may increase the stringency of the Ras response. Genes Dev 19: 1767-1772.

Tong JJ, Schriner SE, McCleary D, Day BJ, Wallace DC. 2007. Life extension through neurofibromin mitochondrial regulation and antioxidant therapy for neurofibromatosis-1 in Drosophila melanogaster. Nat Genet 39: 476-485.

Webber JL, Zhang J, Cote L, Vivekanand P, Ni X, Zhou J, Negre N, Carthew RW, White KP, Rebay I. 2013. The relationship between long-range chromatin occupancy and polymerization of the Drosophila ETS family transcriptional repressor Yan. Genetics 193: 633-649.

Zhang J, Graham TG, Vivekanand P, Cote L, Cetera M, Rebay I. 2010. Sterile $\alpha$ motif domain-mediated self-association plays an essential role in modulating the activity of the Drosophila ETS family transcriptional repressor Yan. Mol Cell Biol 30: 1158-1170. 


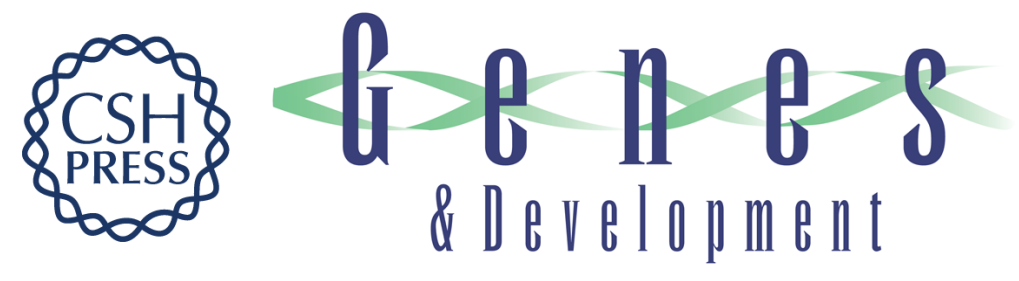

\section{D chromatin interactions organize Yan chromatin occupancy and repression at the even-skipped locus}

Jemma L. Webber, Jie Zhang, Aaron Mitchell-Dick, et al.

Genes Dev. 2013, 27:

Access the most recent version at doi:10.1101/gad.225789.113

Supplemental http://genesdev.cshlp.org/content/suppl/2013/11/01/27.21.2293.DC1
Material

References This article cites 27 articles, 12 of which can be accessed free at: http://genesdev.cshlp.org/content/27/21/2293.full.html\#ref-list-1

Creative This article is distributed exclusively by Cold Spring Harbor Laboratory Press for the first Commons six months after the full-issue publication date (see

License http://genesdev.cshlp.org/site/misc/terms.xhtml). After six months, it is available under a Creative Commons License (Attribution-NonCommercial 3.0 Unported), as described at http://creativecommons.org/licenses/by-nc/3.0/.

Email Alerting Receive free email alerts when new articles cite this article - sign up in the box at the top Service right corner of the article or click here.

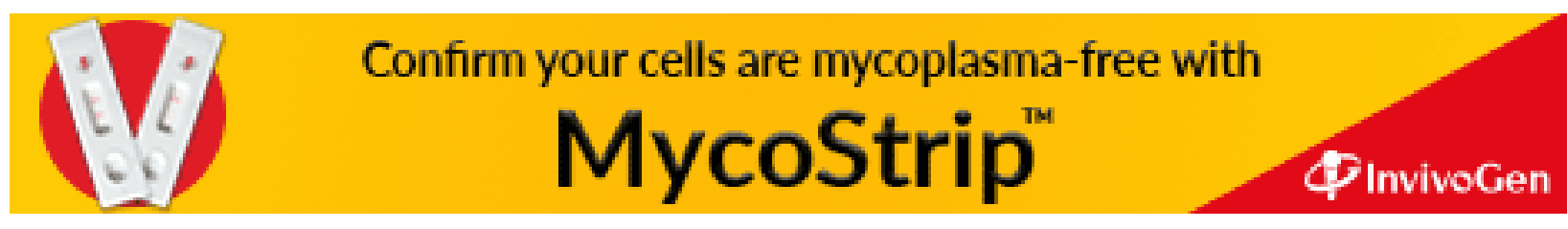

